\title{
Comparison of salivary and serum cortisol levels in mechanically ventilated patients and non-critically ill patients
}

\author{
Jung Hee Kim', Yoon Ji Kim², Sang-Min Lee', Jinwoo Lee' \\ 'Department of Internal Medicine, Seoul National University College of Medicine, Seoul; ${ }^{2}$ Division of Endocrinology and Metabolism, Department of Internal \\ Medicine, Mediplex Sejong Hospital, Incheon, Korea
}

Background: Although the measuring free cortisol is ideal for assessment of hypothalamicpituitary-adrenal function, it is not routinely measured. Salivary cortisol correlates well with the biologically active free cortisol. Therefore, this study measured the morning basal as well as adrenocorticotropic hormone-stimulated salivary cortisol levels in mechanically ventilated patients and compared the results with non-critically ill patients.

Methods: We prospectively enrolled 49 mechanically ventilated patients and 120 patients from the outpatient clinic. Serum and saliva samples were collected between 8 AM and 10 AM. Salivary cortisol levels were measured using an enzyme immunoassay kit. The salivary samples were insufficient in 15 mechanically ventilated patients (30.6\%), and these patients were excluded from the final analysis.

Results: Mechanically ventilated patients $(n=34)$ were significantly older and had lower body mass index and serum albumin levels and higher serum creatinine levels than non-critically ill patients $(n=120)$. After adjustment for these parameters, both basal and stimulated salivary and serum cortisol levels were higher in mechanically ventilated patients. The increase in cortisol was not significantly different between the two groups. Serum cortisol levels showed a positive correlation with salivary cortisol levels. Among mechanically ventilated patients, both basal serum and salivary cortisol levels were lower in survivors than in non-survivors.

Conclusions: Both basal total serum and salivary cortisol levels were elevated in mechanically ventilated patients and in non-survivors.

Key Words: cortisol; hydrocortisone; intensive care units; outpatients; saliva; stress

\section{INTRODUCTION}

Cortisol levels are increased in critically ill patients as a response to severe physical stress. Increased systemic cortisol availability is an important protective response to avoid shock, organ failure, tissue damage, and worsening infection [1]. Critical illness-related corticosteroid insufficiency (CIRCI) is a relative adrenal insufficiency caused by impairment of the hypothalamic-pituitary-adrenal (HPA) axis during critical illness and is associated with increased morbidity, length of intensive care unit (ICU) stay, and mortality [2].

Several factors complicate the assessment of the HPA axis in critically ill patients. Optimal

\section{Original Article}

Received: May 29, 2020

Revised: July 17, 2020

Accepted: August 9, 2020

Corresponding author Jinwoo Lee

Department of Internal Medicine, Seoul National University College of Medicine, 101 Daehak-ro, Jongnogu, Seoul 03080, Korea Tel.: +82-2-2072-7593 Fax: +82-2-762-9662

E-mail: realrain7@gmail.com

Copyright $(\odot 2020$ The Korean Society of Critical Care Medicine

This is an Open Access article distributed under the terms of Creative Attributions Non-Commercial License (https:/I creativecommons.org/li-censes/by-nc/4.0/) which permits unrestricted noncommercial use, distribution, and reproduction in any medium, provided the original work is properly cited. 
cortisol levels are likely to vary according to the patient's condition and the severity of the disease, making it difficult to establish a normal value for such patients. Moreover, most of the circulating cortisol is bound to carrier proteins (corticosteroid-binding globulin and albumin) with less than $10 \%$ in unbound form, which is responsible for the physiologic function of the hormone [3]. Decreased levels of these binding proteins, which are commonly observed in critically ill patients, may affect the measured concentrations of serum total cortisol. Although serum free cortisol is ideal for assessment of HPA function, it is difficult to quantify and, therefore, not routinely used in clinical practices. Salivary cortisol has shown good correlation with biologically-active free cortisol and thus has been accepted as a surrogate measure [4-6]. Therefore, this study aimed to investigate morning basal and adrenocorticotropic hormone (ACTH)-stimulated salivary cortisol levels in mechanically ventilated patients and to compare the results with non-critically ill patients.

\section{MATERIALS AND METHODS}

\section{Study Participants}

We enrolled 49 patients admitted in the medical ICU with acute respiratory failure who were mechanically ventilated. Additionally, 120 non-critically ill patients were enrolled from the outpatient clinic. All patients were prospectively enrolled from April 2013 to December 2014. To prevent confounding factors, patients with a history of bleeding in the oral cavity, oral contraceptive use, and pregnancy were excluded. Among mechanically ventilated patients, patients requiring palliative care or patients with a presumed or documented history of steroid use were excluded.

This study was approved by the Institutional Review Board of Seoul National University Hospital (IRB No. 1303-068-474). All participants provided written informed consent, and the study was conducted in accordance with the tenets of the Declaration of Helsinki.

\section{Salivary and Serum Cortisol Measurement}

The non-critically ill patients were instructed to avoid eating or drinking anything except water, brushing their teeth, or smoking 1 hour before the test. Mechanically ventilated patients were fed via feeding tubes. Basal serum and salivary cortisol samples were collected between $8 \mathrm{AM}$ and $10 \mathrm{AM}$. and the Synacthen test was performed consecutively. Samples from mechanically ventilated patients were obtained within 48 hours of admission to the ICU. Stimulated serum and sali-

\section{KEY MESSAGES}

- Levels of serum cortisol showed good positive correlation with salivary cortisol in both mechanically ventilated and non-critically ill patients.

- Both basal and stimulated salivary and serum cortisol levels were higher in mechanically ventilated patients than in non-critically ill patients.

- Among mechanically ventilated patients, both basal serum and salivary cortisol levels were lower in survivors than in non-survivors.

vary cortisol levels were measured simultaneously 30 and 60 minutes after intravenous administration of $250 \mu \mathrm{g}$ synthetic ACTH (Synacthen; Novartis Pharma, Basel, Switzerland). Basal and stimulated serum blood samples were immediately centrifuged at $4^{\circ} \mathrm{C}$ for 15 minutes, and the resulting plasma was stored at $-20^{\circ} \mathrm{C}$ until used. Plasma total cortisol was measured using a Packard Cobra Gamma Counter analyzer with commercial radioimmunoassay kits (CIS Bio International, France; inter-assay coefficient of variation [CV], 4.7\%; intraassay CV, $4.2 \%$ ). Saliva of non-critically ill patients was collected by chewing an oral cotton swab (Salivette, Sarstedt, Germany) for 2-5 minutes. For mechanically ventilated patients, an oral cotton swab was placed in the mouth until soaked with saliva. The samples were frozen at $-20^{\circ} \mathrm{C}$ until analysis. Salivary cortisol was analyzed using an enzyme immunoassay kit (EIA Salimetrics Inc., State College, PA, USA). The intra-assay coefficient of variation was $3.2 \%-6.3 \%$, and the inter-assay coefficient of variation was $5.7 \%-6.8 \%$. The expected morning ranges of salivary cortisol derived using this kit were 3.1-22.4 nmol/L and $4.1-20.4 \mathrm{nmol} / \mathrm{L}$ in adults aged $51-70$ [7].

\section{Definition of CIRCI}

CIRCI was defined according to the 2017 consensus definition as having a delta cortisol $<9 \mu \mathrm{g} / \mathrm{dl}$ after cosyntropin $(250 \mu \mathrm{g})$ administration or a random serum cortisol of $<10 \mu \mathrm{g} / \mathrm{dl}$ [2].

\section{Statistical Analysis}

Data are presented as mean \pm standard deviation or $\mathrm{n}(\%)$. A Student t-test or Mann-Whitney test was used for continuous variables according to distribution. Chi-square tests were used for categorical variables. The correlation between serum and salivary cortisol was assessed using the Spearman rank correlation analysis. A P-value $<0.05$ was considered statistically significant. All analyses were performed using IBM SPSS ver. 21.0 (IBM Corp., Armonk, NY, USA). 


\section{RESULTS}

A flowchart of the participants examined is presented in Figure 1. Salivary samples were insufficient in 15 patients $(30.6 \%)$ of the 49 mechanically ventilated patients that were enrolled. Therefore, a total of 120 non-critically ill patients and 34 mechanically ventilated patients were enrolled for the final analysis. Clinical and biochemical parameters of these patients are compared in Table 1. Mechanically ventilated patients were

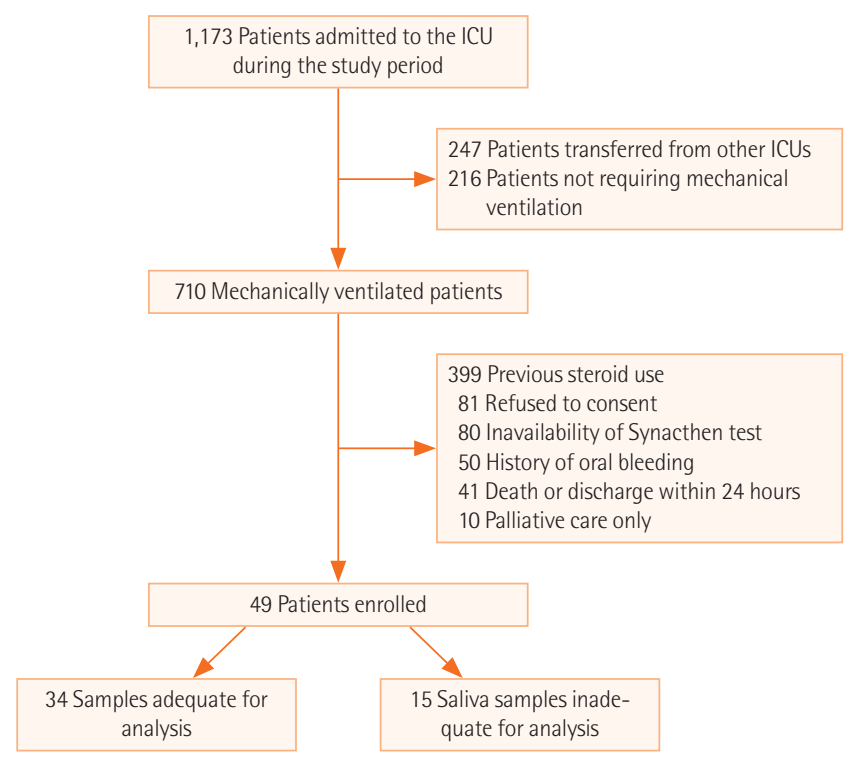

Figure 1. Flowchart of study participants in the intensive care unit (ICU). significantly older and had lower body mass index (BMI), serum albumin levels, and plasma ACTH levels and higher serum creatinine levels compared to non-critically ill patients. Among the mechanically ventilated patients, one patient (3.1\%) had an underlying liver disease and three (9.4\%) had kidney diseases. Pneumonia was the likely cause of acute respiratory failure in most patients (91.2\%). The mean Acute Physiology and Chronic Health Evaluation (APACHE) II score was 25 \pm 9.7 . None of the non-critically ill patients had liver or kidney diseases. Both basal and stimulatory serum and salivary cortisol levels were significantly higher in the mechanically ventilated patients. Contrary to the increment in serum cortisol, the increase in salivary cortisol was not different between the two groups.

After adjustment for age, sex, BMI, serum albumin, and creatinine, both basal and stimulated cortisol levels continued to remain higher in the mechanically ventilated patients (Table 2). Statistically significant differences were observed in both serum and salivary cortisol concentrations. However, neither the increase in serum or salivary cortisol varied between the two groups.

Serum cortisol levels showed a positive correlation with salivary cortisol levels in the study population (Figure 2). The positive relationship between stimulated serum and salivary cortisol levels was stronger than that between basal serum and salivary cortisol levels $(r=0.750$ and $r=0.538$, respectively; all $\mathrm{P}<0.001)$.

The all-cause 28-day mortality of the mechanically ventilat-

Table 1. Clinical and biochemical parameters of non-critically ill patients and mechanically ventilated patients

\begin{tabular}{|c|c|c|c|}
\hline Variable & $\begin{array}{l}\text { Non-critically ill patient } \\
\qquad(n=120)\end{array}$ & $\begin{array}{l}\text { Mechanically ventilated } \\
\text { patient }(n=34)\end{array}$ & P-value \\
\hline Age (yr) & $54.8 \pm 15.3$ & $64.4 \pm 13.7$ & 0.002 \\
\hline Female sex & 70 (58.3) & $12(35.3)$ & 0.034 \\
\hline Body mass index $\left(\mathrm{kg} / \mathrm{m}^{2}\right)$ & $24.0 \pm 4.0$ & $21.2 \pm 3.9$ & $<0.001$ \\
\hline Serum albumin $(g / d l)^{a}$ & $4.2 \pm 0.5$ & $2.7 \pm 0.4$ & $<0.001$ \\
\hline Serum creatinine $(\mathrm{mg} / \mathrm{dll})^{\mathrm{a}}$ & $0.82 \pm 0.24$ & $1.80 \pm 2.22$ & $<0.001$ \\
\hline Plasma ACTH (pmol/L) & $10.2 \pm 11.0$ & $6.2 \pm 5.4$ & 0.026 \\
\hline Basal serum cortisol (nmol/L) & $297.1 \pm 184.1$ & $568.2 \pm 293.5$ & $<0.001$ \\
\hline Peak serum cortisol (nmol/L) & $695.3 \pm 302.6$ & $865.3 \pm 340.4$ & 0.005 \\
\hline Basal salivary cortisol (nmol/L) & $6.1 \pm 5.1$ & $46.7 \pm 37.2$ & $<0.001$ \\
\hline Peak salivary cortisol (nmol/L) & $21.1 \pm 14.6$ & $64.8 \pm 37.4$ & $<0.001$ \\
\hline Increment of serum cortisol (nmol/L) & $398.2 \pm 214.5$ & $281.5 \pm 217.4$ & 0.008 \\
\hline Increment of salivary cortisol (nmol/L) & $14.9 \pm 13.6$ & $20.4 \pm 21.9$ & 0.177 \\
\hline
\end{tabular}

Values are presented as mean \pm standard deviation or number $(\%)$.

ACTH: adrenocorticotropic hormone.

${ }^{a}$ Serum albumin and creatinine levels were unavailable in nine non-critically ill patients. 
Table 2. Serum and salivary cortisol response between non-critically ill patients and mechanically ventilated patients after adjustment for age, sex, body mass index, albumin, and creatinine

\begin{tabular}{lccc}
\hline Variable & $\begin{array}{c}\text { Non-critically ill patient }{ }^{2} \\
(\mathrm{n}=111)\end{array}$ & $\begin{array}{c}\text { Mechanically ventilated } \\
\text { patient }(\mathrm{n}=34)\end{array}$ & P-value \\
\hline Basal serum cortisol $(\mathrm{nmol} / \mathrm{L})$ & $298.2 \pm 188.9$ & $571.4 \pm 297.3$ & 0.014 \\
Peak serum cortisol $(\mathrm{nmol} / \mathrm{L})$ & $682.1 \pm 309.2$ & $852.9 \pm 337.4$ & 0.034 \\
Basal salivary cortisol $(\mathrm{nmol} / \mathrm{L})$ & $6.2 \pm 5.3$ & $42.9 \pm 29.7$ & $<0.001$ \\
Peak salivary cortisol $(\mathrm{nmol} / \mathrm{L})$ & $20.7 \pm 14.7$ & $63.3 \pm 36.8$ & $<0.001$ \\
Increment of serum cortisol $(\mathrm{nmol} / \mathrm{L})$ & $383.9 \pm 210.4$ & $281.5 \pm 217.4$ & 0.528 \\
Increment of salivary cortisol $(\mathrm{nmol} / \mathrm{L})$ & $14.5 \pm 13.5$ & $20.4 \pm 21.9$ & 0.284 \\
\hline
\end{tabular}

Values are presented as mean \pm standard deviation.

${ }^{2}$ Data from nine non-critically ill patients without serum albumin and creatinine levels were excluded from analysis.
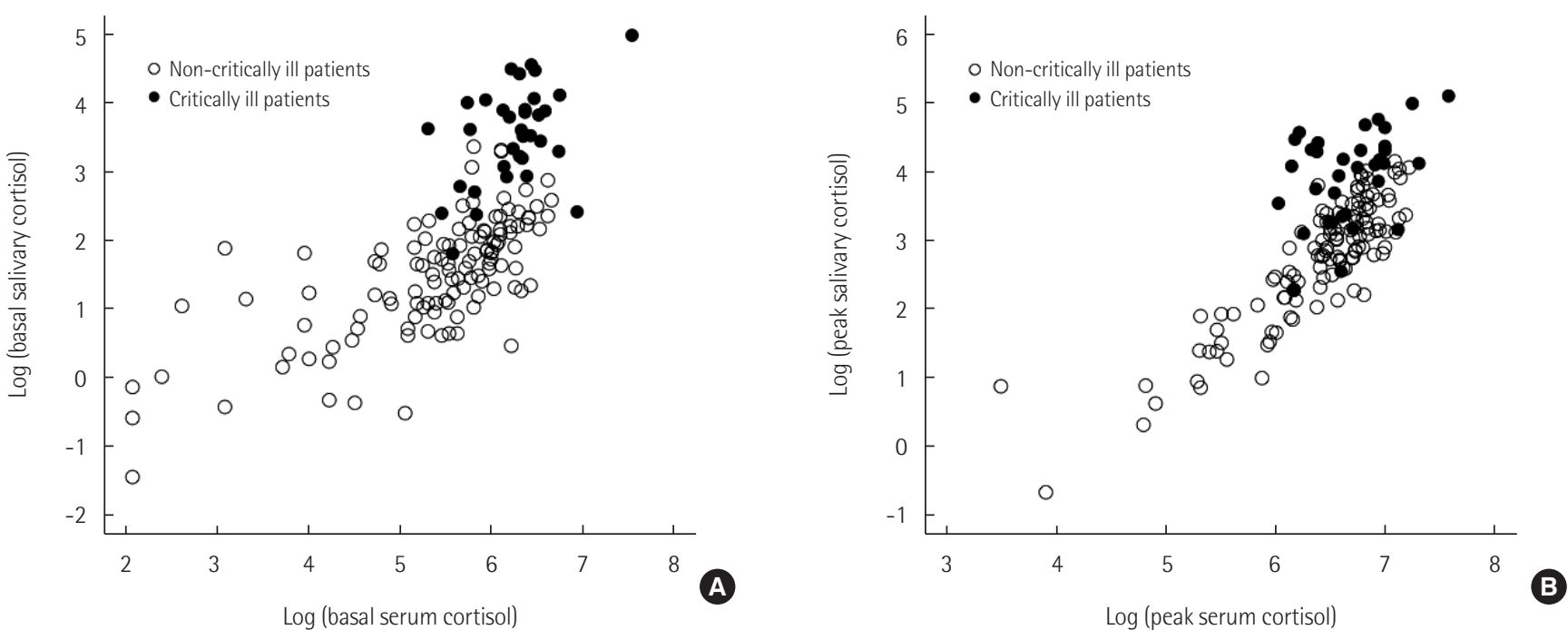

Figure 2. Scatter plot between basal (A) or stimulated serum (B) and salivary cortisol levels.

Table 3. Characteristics of mechanically ventilated patients $(n=34)$, comparing survivors to non-survivors

\begin{tabular}{lccc}
\hline Variable & Survivor $(\mathrm{n}=28)$ & Non-survivor $(\mathrm{n}=6)$ & P-value \\
\hline Age $(\mathrm{yr})$ & $63.3 \pm 14.9$ & $68.0 \pm 7.2$ & 0.099 \\
Female sex & $9(32.1)$ & $3(50)$ & 0.414 \\
Body mass index $\left(\mathrm{kg} / \mathrm{m}^{2}\right)$ & $21.3 \pm 3.9$ & $20.7 \pm 3.9$ & 0.748 \\
SOFA score & $8.8 \pm 4.2$ & $11.8 \pm 3.8$ & 0.161 \\
Duration of ICU stay (day) & $9.4 \pm 6.7$ & $8.7 \pm 6.0$ & 0.811 \\
Duration of MV (day) & $6.6 \pm 6.7$ & $6.0 \pm 3.6$ & 0.826 \\
Basal serum cortisol $(\mathrm{nmol} / \mathrm{L})$ & $539.5 \pm 201.5$ & $720.1 \pm 575.9$ & 0.011 \\
Peak serum cortisol $(\mathrm{nmol} / \mathrm{L})$ & $860.0 \pm 281.5$ & $833.7 \pm 568.1$ & 0.121 \\
Basal salivary cortisol $(\mathrm{nmol} / \mathrm{L})$ & $37.6 \pm 23.5$ & $67.3 \pm 44.7$ & 0.049 \\
Peak salivary cortisol $(\mathrm{nmol} / \mathrm{L})$ & $59.5 \pm 44.0$ & $80.5 \pm 47.5$ & 0.494 \\
Increment of serum cortisol $(\mathrm{nmol} / \mathrm{L})$ & $317.5 \pm 216.2$ & $113.6 \pm 136.1$ & 0.273 \\
Increment of salivary cortisol $(\mathrm{nmol} / \mathrm{L})$ & $21.9 \pm 23.8$ & $13.2 \pm 5.1$ & 0.011 \\
\hline
\end{tabular}

Values are presented as mean \pm standard deviation or number (\%).

SOFA: Sequential Organ Failure Assessment; ICU: intensive care unit; MV: mechanical ventilation. 
ed patients was $18.8 \%(6 / 34)$. The comparison of serum and salivary cortisol concentrations in survivors and non-survivors are shown in Table 3. There was a significant difference in basal serum cortisol levels between the survivors and the nonsurvivors (539.5 \pm 201.5 vs. $720.1 \pm 575.9 \mathrm{nmol} / \mathrm{L} ; \mathrm{P}=0.011$ ) Basal salivary cortisol levels were also lower in survivors than in non-survivors ( $37.6 \pm 23.5$ vs. $67.3 \pm 44.7 \mathrm{nmol} / \mathrm{L} ; \mathrm{P}=0.049$ ). The increase in salivary cortisol levels was significantly higher in survivors than in non-survivors $(21.9 \pm 23.8$ vs. $13.2 \pm 5.1 \mathrm{nmol} /$ $\mathrm{L} ; \mathrm{P}=0.011$ ). According to the 2017 consensus definition, 19 of the mechanically ventilated patients $(55.9 \%)$ were diagnosed with CIRCI [2]. Among the survivors, 14 patients (50\%) were diagnosed with CIRCI compared with five patients (83.3\%) among non-survivors.

\section{DISCUSSION}

Compared with non-critically ill patients, mechanically ventilated patients had both higher basal and peak serum and salivary cortisol levels. Among the mechanically ventilated patients, basal serum and salivary cortisol levels were significantly higher than those in non-survivors. Although not statistically significant in serum, the increment of cortisol was significantly lower in saliva from non-survivors. These findings suggest that basal cortisol levels are associated with the severity of the initial stressor and that insufficient adrenal reserve and a diminished HPA response to this severe stress result in a grave prognosis. Similar results have been shown in critically ill adults and children, reporting that high basal serum cortisol levels are associated with increased mortality [8-11].

It is difficult to compare the salivary cortisol levels of critically ill patients. There is a more than 6 -fold difference in mean salivary cortisol levels of patients with severe sepsis [12,13]. The salivary cortisol levels of the mechanically ventilated patients in this study were higher than the levels found in the general critically ill population [14] but lower than the levels of patients with severe sepsis $[12,13,15]$.

The appeal of measuring salivary cortisol in the ICU is because it is more reliable in critically ill patients and patients with hypoproteinemia [14-16]. Our study also showed a positive correlation between serum and salivary cortisol levels both before and after stimulation. Unfortunately, saliva collection is not always feasible in the ICU. In our study, the amount of saliva was insufficient in 15 mechanically ventilated patients (30.6\%), whereas all samples from non-critically ill patients were adequate for analysis. The adequacy of salivary samples in critically ill patients varies among different studies. This may be associated with the presence of mechanical ventilation, poor oropharyngeal hygiene, and lack of oral intake. In a study reporting a low proportion (5.6\%) of inadequate samples, only $41 \%$ of the patients were mechanically ventilated [14]. In contrast, other studies have consistently reported difficulties in obtaining sufficient saliva samples in critically ill patients [17-19].

Basal cortisol levels were significantly higher in mechanically ventilated patients and in non-survivors than in non-critically ill patients and survivors. Cortisol increases and peak cortisol concentrations did not show the consistent differences that basal cortisol concentrations did. Assessment of the HPA axis with $250 \mu \mathrm{g}$ ACTH stimulation may be troublesome and impractical in the ICU, as the test results are likely to be confounded by the increase in cortisol distribution volume [1]. In cases where saliva sampling is not feasible, basal serum total cortisol may be sufficient to assess critically ill patients. Although mechanically ventilated patients have lower albumin levels, basal serum total cortisol levels are still significantly higher and are associated with a grave prognosis.

Recent guidelines have recommended using either random serum total cortisol or delta serum cortisol to diagnose CIRCI and have suggested against using salivary cortisol in place of serum cortisol due to low quality of evidence [2]. Moreover, the guidelines do not recommend using the diagnosis of CIRCI to influence the decision to treat patients with corticosteroids. This, in turn, suggests that the diagnostic criteria of CIRCI may need revision to correctly identify patients at risk. More than half of our mechanically ventilated patients had CIRCI, and the presence of CIRCI was not associated with increased mortality. Other studies have also shown that the presence of CIRCI does not affect the outcome of critically ill patients [2022]. Another interesting finding of this study was that that delta salivary cortisol, but not the delta serum cortisol, was significantly higher in survivors than in non-survivors. There is a possibility that the increment of salivary cortisol may be used along with serum total cortisol to better define CIRCI. Further studies are needed to elucidate the clinical significance of high delta salivary cortisol levels.

One of the limitations of this study was the small sample size of mechanically ventilated patients. Studies on levels of salivary cortisol in mechanically ventilated patients with high severity scores are rare. Additionally, cortisol levels and stimulation tests were performed only once for each patient. Although the present study cannot address the changes in HPA axis function during the course of illnesses, it provides an insight into the acute phase of the disease. Also, this study pro- 
vided a valuable assessment of salivary sampling feasibility for mechanically ventilated patients. In conclusion, both basal total serum and salivary cortisol levels are elevated in mechanically ventilated patients and in non-survivors.

\section{CONFLICT OF INTEREST}

No potential conflict of interest relevant to this article was reported.

\section{ACKNOWLEDGMENTS}

This work was supported by Research Resettlement Fund for the new faculty of Seoul National University Hospital (grant no. 800-20150328).

\section{ORCID}

Jung Hee Kim

https://orcid.org/0000-0003-1932-0234

Yoon Ji Kim https://orcid.org/0000-0001-9730-4120

Sang-Min Lee https://orcid.org/0000-0002-1388-9318

Jinwoo Lee https://orcid.org/0000-0003-0958-106X

\section{AUTHOR CONTRIBUTIONS}

Conceptualization: JHK, JL. Data curation: JHK. Formal analysis: YJK, JL. Funding acquisition: JL. Methodology: JHK, JL. Project administration: JL. Visualization: all authors. Writingoriginal draft: JHK, YJK, JL. Writing-review \& editing: all authors.

\section{REFERENCES}

1. Téblick A, Peeters B, Langouche L, Van den Berghe G. Adrenal function and dysfunction in critically ill patients. Nat Rev Endocrinol 2019;15:417-27.

2. Annane D, Pastores SM, Rochwerg B, Arlt W, Balk RA, Beishuizen A, et al. Guidelines for the diagnosis and management of critical illness-related corticosteroid insufficiency (CIRCI) in critically ill patients (Part I): Society of Critical Care Medicine (SCCM) and European Society of Intensive Care Medicine (ESICM) 2017. Intensive Care Med 2017;43:175163.

3. Hamrahian AH, Oseni TS, Arafah BM. Measurements of serum free cortisol in critically ill patients. N Engl J Med 2004; 350:1629-38.

4. Raff H. Utility of salivary cortisol measurements in Cushing's syndrome and adrenal insufficiency. J Clin Endocrinol Metab 2009;94:3647-55.

5. Aardal-Eriksson E, Karlberg BE, Holm AC. Salivary cortisol: an alternative to serum cortisol determinations in dynamic function tests. Clin Chem Lab Med 1998;36:215-22.

6. Perogamvros I, Keevil BG, Ray DW, Trainer PJ. Salivary cortisone is a potential biomarker for serum free cortisol. J Clin Endocrinol Metab 2010;95:4951-8.

7. Aardal E, Holm AC. Cortisol in saliva: reference ranges and relation to cortisol in serum. Eur J Clin Chem Clin Biochem 1995;33:927-32.

8. Levy-Shraga Y, Pinhas-Hamiel O, Molina-Hazan V, TamirHostovsky L, Eini ZM, Lerner-Geva L, et al. Elevated baseline cortisol levels are predictive of bad outcomes in critically ill children. Pediatr Emerg Care 2018;34:613-7.

9. Bekhit OE, Mohamed SA, Yousef RM, AbdelRasol HA, Khalaf NA, Salah F. Relation between baseline total serum cortisol level and outcome in pediatric intensive care unit. Sci Rep 2019;9:6008

10. Vassiliadi DA, Dimopoulou I, Tzanela M, Douka E, Livaditi O, Orfanos SE, et al. Longitudinal assessment of adrenal function in the early and prolonged phases of critical illness in septic patients: relations to cytokine levels and outcome. J Clin Endocrinol Metab 2014;99:4471-80.

11. Pandya U, Polite N, Wood T, Lieber M. Increased total serum random cortisol levels predict mortality in critically ill trauma patients. Am Surg 2014;80:1112-8.

12. Mello RC, Sad EF, Andrade BC, Neves SP, Santos SM, Sarquis MM, et al. Serum and salivary cortisol in the diagnosis of adrenal insufficiency and as a predictor of the outcome in patients with severe sepsis. Arq Bras Endocrinol Metabol 2011; $55: 455-9$

13. Elbuken G, Karaca Z, Tanriverdi F, Unluhizarci K, Sungur M, Doganay M, et al. Comparison of total, salivary and calculated free cortisol levels in patients with severe sepsis. J Intensive Care 2016;4:3

14. Arafah BM, Nishiyama FJ, Tlaygeh H, Hejal R. Measurement of salivary cortisol concentration in the assessment of adrenal function in critically ill subjects: a surrogate marker of the circulating free cortisol. J Clin Endocrinol Metab 2007;92:2965 71.

15. Estrada-Y-Martin RM, Orlander PR. Salivary cortisol can replace free serum cortisol measurements in patients with septic shock. Chest 2011;140:1216-22.

16. Raff H, Brock S, Findling JW. Cosyntropin-stimulated salivary cortisol in hospitalized patients with hypoproteinemia. Endocrine 2008;34:68-74. 
17. Puglisi S, Pizzuto A, Laface B, Panero F, Aprà F, Palmas E, et al. Determination of salivary cortisol to assess time-related changes of the adrenal response to stress in critically ill patients. Eur J Intern Med 2019;68:66-70.

18. Bartanusz V, Corneille MG, Sordo S, Gildea M, Michalek JE, Nair PV, et al. Diurnal salivary cortisol measurement in the neurosurgical-surgical intensive care unit in critically ill acute trauma patients. J Clin Neurosci 2014;21:2150-4.

19. Duplessis C, Rascona D, Cullum M, Yeung E. Salivary and free serum cortisol evaluation. Mil Med 2010;175:340-6.
20. Bruno JJ, Hernandez M, Ghosh S, Pravinkumar SE. Critical illness-related corticosteroid insufficiency in cancer patients. Support Care Cancer 2012;20:1159-67.

21. Salluh JI, Shinotsuka CR, Soares M, Bozza FA, Lapa e Silva JR, Tura BR, et al. Cortisol levels and adrenal response in severe community-acquired pneumonia: a systematic review of the literature. J Crit Care 2010;25:541.e1-8.

22. Song JH, Kim JH, Lee SM, Lee J. Prognostic implication of adrenocortical response during the course of critical illness. Acute Crit Care 2019;34:38-45. 